\title{
A HISTÓRIA NATURAL DA DITADURA
}

\author{
Karl Erik Schollhammer
}

Pontifícia Universidade Católica (PUC-Rio), Rio de Janeiro, RJ - Brasil.

$<$ karlerikschollhammer@me.com>

http://dx.doi.org/10.1590/ 0102-64450039-054/96

O encerramento dos trabalhos da Comissão Nacional da Verdade em 2014, por ocasião do cinquentenário da instalação de uma ditadura militar no Brasil, convida para uma reflexão sobre o papel das artes e da literatura diante da memória autoritária. Este ensaio analisará como a violência, as infrações dos direitos humanos, que em escala mundial só demonstram aumentar e piorar, e a barbárie do autoritarismo não extinta com a democracia política aparecem na literatura.

A literatura sempre teve importante papel de testemunho e de memória desse tipo de atrocidades ao oferecer vivências afetivas de realidades, que, em uma narrativa fria da história, frequentemente são reduzidas à escala pasteurizada dos eventos políticos ou exploradas comercialmente na extrapolação midiática de seus efeitos mais espetaculares.

\section{K. - Relato de uma busca, de Bernardo Kucinski}

Exemplo recente é o romance $K$. - Relato de uma busca, de Bernardo Kucinski, originalmente lançado em 2011, e que, 
em várias traduções - alemão, espanhol, italiano e hebraico, entre outras -, já ganhou ampla divulgação internacional. No Brasil, o romance foi finalista em concursos literários importantes - Portugal Telecom e São Paulo de Literatura, ambos de 2012 - e, com seu relançamento em 2014, obteve novo destaque e divulgação pela atualidade do tema de que trata.

Em uma estrutura fragmentária de textos curtos, desenvolve-se uma história situada em São Paulo, em 1974, sobre um pai judeu que vive a desaparição da filha, universitária e militante de uma organização de esquerda. No prefácio do romance, o autor salienta a ficcionalidade da narrativa, apesar de ser resultado de um trabalho de memória da desaparição da própria irmã nas mãos das forças repressivas da ditadura militar. Kucinski, professor aposentado da Universidade de São Paulo (USP), jornalista, conselheiro do primeiro governo Lula e cientista político conhecido, se 40 inspira na história real vivida pelo pai, polonês refugiado do nazismo no Brasil, e cria assim uma relação histórica de paralelismo entre o fascismo alemão e a repressão da ditadura brasileira. Um paralelo que despertou interesse internacional no lançamento da tradução alemã do romance durante a Feira do Livro de Frankfurt de 2014. O interessante aqui é observar a maneira com que a narrativa constrói sua referência histórica em uma aposta realista sustentada sobre alicerces significativos.

Em primeiro lugar, de uma simulação documental biográfica, apoiada em registros fragmentários e ficcionais narrados em terceira pessoa sobre o desaparecimento da filha do personagem. Ao assumir ficcionalmente o olhar do próprio pai, Kucinski cria uma estrutura textual complexa, não linear e elíptica, que arma a trama, com tons kafkianos, a partir do esforço patético contra a burocracia do poder, de uma pessoa cada vez mais investida na procura da filha desaparecida. A crescente obsessão na busca insistente do 
personagem arma um forte apelo afetivo para o leitor diante daquilo que permanece indizível e nunca explicitado descritivamente nas evidências textuais: os fatos consumados, penosamente previsíveis - o sequestro e assassinato da filha por agentes da ditadura. Trata-se assim de um testemunho simulado de uma experiência real de fatos históricos conhecidos, que mistura a referência histórica real e factual com a vivência subjetiva e emotiva de modo bastante característico para o realismo histórico na literatura. É verdade que o romance se distancia do romance histórico tradicional pela facilidade com que abre mão dos detalhes documentais e sua proposta ficcional não é revisar fatos nem combater revisionismos de uma história que é, em grande parte, consensual, apesar de todas as divergências ideológicas que sua interpretação política e contextual também possui. Sua originalidade enquanto narrativa encontra-se muito mais na interpretação dos dilemas afetivos vividos pelo personagem do pai, os quais se desenvolvem ao longo do percurso frustrado e reconfigura o perfil de sua identidade.

Talvez possamos considerar a narrativa um trabalho de luto vicário de alguém que sofreu a perda da irmã e do cunhado e, simultaneamente, presenciou a incompreensão do drama vivido pelo pai. Não importa, a transferência da história vivida na ficção pelo pai para a história não relatada do autor, personagem implícito do romance, representa um enorme apelo afetivo para o leitor ao mesmo tempo que produz um efeito contundente de veracidade realista.

Em lugar da ficção histórica, cujas descrições livres permitem preencher os fatos ignorados pelos historiadores, o relato de Kucinski ganha autenticidade numa construção literária minimalista da própria falha constitutiva do testemunho subjetivo, incompleto e inacessível. Lançando mão de uma estrutura fragmentária, com uma narrativa elaborada na tradição estética modernista, insinua e encena os impedimentos na denúncia do conteúdo explícito da his- 
tória, por ser submetido à estrutura traumática, condição impossível de experiência diante do real histórico. Dessa maneira, o romance concilia, em um coquetel poderoso, os extremos do documentarismo memorialista fiel aos fatos objetivos da repressão política durante o governo militar com a vivência afetiva do testemunho subjetivo do pai, simulado pela construção ficcional.

"Até os nazistas, que reduziam suas vítimas a cinzas, registravam os mortos", observa o narrador, mas, na ditadura militar, "as pessoas desapareciam sem deixar vestígios" (Kucinski, 2012, p. 27). É a construção e preenchimento desse vazio que o autor procura através de um conjunto de formas breves e textos de gêneros diversos, recompilados em uma estrutura arquivista, documentos, cartas, transcrições, memórias de diário, conversas, falas de agentes da repressão, atas de reuniões universitárias, mensagens da clandestinidade, informes, relatos de encontros e, final42 mente, um post scriptum do próprio autor sobre a impossibilidade de colocar um ponto final e de representar e superar o cerne da angústia. Eis a dificuldade que organiza a estrutura desconexa como um espelho da impossibilidade representativa de uma vivência cujo impedimento reflete, de certa maneira, a impossibilidade traumática de expressar a violência sofrida pela filha do protagonista.

K. chegou a compor vários cartões com registros de episódios, diálogos, cenários. Mas ao tentar reuni-los numa narrativa coerente algo não funcionou. Não conseguia expressar os sentimentos que dele se apossaram em muitas situações pelas quais passara, por exemplo, no encontro com o arcebispo.

Era como se faltasse o essencial; era como se as palavras, embora escolhidas com esmero, em vez de mostrar a plenitude do que ele sentia, ao contrário, escondessem ou amputassem o significado principal (Kucinski, 2012, p. 133). 
Aproximando-se dessa maneira de uma poética do indizível para dar conta do trauma, a narrativa constrói uma referencialidade subjetiva, que, ao expor as limitações da consciência do sujeito diante do real da vivência testemunhada, ganha um novo crédito que o depoimento e a narrativa em primeira pessoa há muito perdera. Em outros exemplos contemporâneos, de modo notório no romance premiado de Michel Laub - $O$ diário da queda -, essa mesma figura narrativa se trivializa e abre um amplo terreno de simulação ficcional do trauma subjetivo, não de sua realidade, senão de seu sintoma, que, de modo tranquilo, se alia com as ambições de experimentação formal e sucesso comercial. Não se trata de questionar a importância histórica do testemunho como figura heurística na apropriação de memórias da história política, apenas se observa o esvaziamento que acompanha a popularização de seu modus operandi na cultura contemporânea de subjetividades sobre-expostas e que joga a perder o ganho já havido pela literatura, agora reencontrado em uma voz autêntica de depoimento e denúncia.

Alguns fragmentos textuais do livro de Kucinski adquirem características de documentos: atas, cartas, transcrições de diálogos, entradas de diários e outros aparentes restos textuais resgatados de um arquivo real ou imaginário, formatos discursivos que oferecem uma "realidade" indexical ou indicial aos fragmentos. Sua aparição documental como vestígios da história se sobrepõe à função representativa e também à bela forma retórica e narrativa da escrita que antes era fundamental para a elaboração literária do texto. Percebe-se uma simulação da realidade textual que converte os fragmentos em resíduos narrativos de um percurso pelos corredores da máquina do poder estatal, cuja violência se expressa tanto no discurso de recusa quanto nas ações sigilosas da repressão militar e policial. Produz-se, 
assim, uma espécie de materialidade ou substância discursiva, cuja realidade histórica não se encontra apenas na simulação de seu conteúdo significativo, mas na sua forma fragmentada de resto arquivístico. Os fragmentos textuais equivalem a outros dejetos cotidianos - um pedaço de jornal, um fragmento de escrita, um guardanapo anotado -, inseridos na elaboração ficcional da história.

O efeito dessa inserção é uma descontinuidade que, por um lado, foi visto pelos críticos como um comentário metaficcional aos perigos da representação, à maneira dos pintores modernistas quando introduziam um pedaço de manchete real na pintura de um jornal sobre uma mesa de café. Mas como bem observou Jacques Rancière, não se trata nessa composição apenas de exaltar seu valor documental, senão de flagrar uma potencialidade dupla de historicidade que acompanha qualquer objeto na era da história e, certamente, também os objetos textuais em sua natureza de 44 objeto linguístico perceptível. A história está embutida na coisa em sua materialidade e também dobrada na potencialidade de criar destinos que, na composição da narrativa, se acoplam a outros fragmentos. No momento em que se libera a história de sua característica de exemplo e a narrativa da história de sua composição formal de "submissão à representação, multiplicam-se as possibilidades figurativas que todas as formas de desfiguração usufruem" (Rancière, 2014, p. 81; tradução do autor).

É dessa maneira que surge, nesse formato de romance, um texto com características expressivas que abrem mão da hegemonia da representação para criar na leitura uma espécie de cenário afetivo dos restos textuais, induzindo assim ao impacto corporal da performatividade, uma espécie de corredor polonês a ser percorrido sob o efeito de atos linguísticos "quase reais" ou "quase objetivos", que, simultaneamente, alavancam a experiência "quase viva" da realidade intrínseca à representação. Assim, o romance 
de Kucinski realiza uma das utopias construtivistas do modernismo: a criação de uma obra literária toda feita de materiais avulsos e residuais de um mundo em descomposição. Além disso, dirige esse projeto criticamente contra a própria "literatura", representada no romance pelas ambições de bem escrever poeticamente do personagem principal, ao romper com as estruturas tradicionais de gênero, com a estilística e com a verosimilhança representativa. $\mathrm{Na}$ literatura brasileira, essa combinação que reformata uma das tensões criativas do modernismo está presente, por exemplo, no romance de Luiz Ruffato, Eles eram muitos cavalos, de 2001, que também concilia a experimentação expressiva da escrita modernista com um compromisso realista de trazer para dentro da obra a realidade em sua concretude de índice ou vestígio material, elaborando assim uma estrutura romanesca complexa, com materiais de certo modo antirrepresentativos. A diferença no romance de Kucinski é a força da própria história, no caso levada pelos encadeamentos racionais da ditadura militar em sua lógica cruel e repressiva de silêncio, que atua de modo contraditório no cerne da dinâmica narrativa. No texto citado de Jacques Rancière (2014), o filósofo argui que a potência particular da história é de consumar qualquer forma existente da literatura, ao mesmo tempo que a destrói e a elimina. Confere sobre toda matéria sem forma, assim como faz sobre toda escrita estabelecida, "a possibilidade de ser convertida em um elemento no jogo das formas. A era da antirrepresentação não é a era do irrepresentável. É a era do alto realismo" (Rancière, 2014, p. 81; tradução do autor).

\section{História natural da ditadura, de Teixeira Coelho}

Em contraste com a voz narrativa investida na imersão subjetiva na história política e repressiva, expressa no romance de Kucinski, outra dimensão de escrita se abre 
no romance História natural da ditadura, do paulista Teixeira Coelho (2006), também professor da USP e reconhecido crítico de arte.

Trata-se de um romance-ensaio em cinco partes, ou um volume contendo cinco "livros", como diz o próprio narrador ao final do romance. Um vasto material autobiográfico e memorialístico é submetido a um discurso analítico e ensaístico, cujo alvo é explorar a estrutura política da ditadura militar e do autoritarismo do século XX de modo geral. Como no exemplo do romance $K$., há aqui também certa construção analógica entre diferentes momentos repressivos e revoltosos, a começar pelo surgimento do fascismo alemão, abordado já no primeiro livrinho intitulado "Portbou", no qual se discute a morte de Walter Benjamin na cidade de mesmo nome, seguido pela referência à ditadura argentina, tema do segundo livro, "Sur", que gira em torno da amizade entre o narrador e o artista plástico argentino León Ferrari 46 e sua denúncia dos abusos do governo militar argentino. No terceiro livro, "30", discute-se a violência revolucionária e autoritária na Itália da década de 1970, protagonizada por organizações radicais como o Potere operaria e, no quarto livro, "Teoria da tristeza", as memórias dos tempos de residência em Paris sob o impacto dos movimentos estudantis são costurados por uma complexa discussão entre esses eventos históricos e referências a obras da arte ocidental de Tintoretti e Turner a Luis Malle e Visconti e conceitos de análise política de Walter Benjamin a Giorgio Agamben.

Seria impossível dar conta aqui dessa miríade de fios tecidos pela memória pessoal e subjetiva, entremeados por reflexões ensaísticas e cuja estrutura anacrônica, descontínua e descentrada é um dos temas do livro. Seu próprio movimento proliferativo em que as frases se desdobram sempre do seu interior, com a multiplicação de orações subordinadas, descontrolam e desafiam a sequência lógica e racional das frases principais. De modo errático, 
esse movimento de desdobramentos acelerados atrasa os argumentos definidos a favor de cadeias sugestivas e associativas, que permitem misturar as memórias do passado com um raciocínio no presente, sem fechar a estrutura narrativa e sequencial.

Assim, se misturam dois níveis claramente polares, uma memória pessoal e autobiográfica que, como uma longa viagem de muitos encontros, amores, vivências e passagens, se entrelaça com aprendizagens na filosofia, na história da arte e nas lutas políticas, propulsando uma discussão teórica que tematiza as condições de possibilidade de seu projeto literário. Esse outro nível se identifica na costura discursiva entre a história política e as diferentes meadas das histórias biográficas e autobiográfica. $\mathrm{O}$ narrador principal, em primeira pessoa, muitas vezes acompanhado pela namorada Ana M., é claramente um "eu" ensaístico que assina com o nome do autor. A realidade dos eventos históricos se mistura com os relatos ficcionais ou ao menos recontados.

Mas de que maneira é um livro sobre a ditadura? $\mathrm{O}$ autor não pretende ser um protagonista na luta contra o autoritarismo, seu testemunho é mais um depoimento de alguém que participou pouco ou nada no processo político, mas que aqui relata a história dessa periferia ou linha de fuga de quem se afasta do centro dos acontecimentos. Por outro lado, é um relato que continuamente se coloca como interrogação sobre a lógica intrínseca da ditadura e das revoluções políticas, seja falando da Revolução de 30 (que levou Getúlio Vargas ao poder), do fascismo italiano ou das ditaduras militares argentina e brasileira, sempre se esforçando por extrair as figuras e padrões estruturais dessa constelação de poder, cuja natureza aparentemente é de se repetir ao longo da história. Em função conjunta desse esforço analítico, do estilo narrativo de romance e dos temas flutuantes abordados por quem não está necessariamente numa posição privilegiada diante deles, se pode identificar 
nesse livro uma alternativa ao relato testemunhal que tem protagonizado a maior parte da literatura sobre a ditadura militar no continente americano e cujo representante mais recente talvez seja Bernardo Kucinski.

É sabido que a "era do testemunho" - nas palavras de Shoshana Felman e Dori Laub (1991) - se inicia com o processo contra Eichmann em Jerusalém, em 1961, em que se permitia o depoimento de testemunhas oculares de sobreviventes, os quais ofereciam uma denúncia muito mais emocional do que o processo de Nuremberg no final da década de 1940, quando só se admitia a apresentação objetiva de evidências documentais. As características desse novo testemunho e sua relação com a exploração do trauma e com uma cultura da memória foram amplamente analisadas em âmbito nacional e internacional e o impacto de sua figura epistemológica extrapolou as fronteiras do jurídico e do político, deixando sua marca nítida na literatura, no cine48 ma e em toda a indústria de entretenimento.

\section{As obras de Kucinski e Teixeira Coelho e a ossada de Mengele}

Para ajudar na comparação entre as duas obras literárias em questão, é importante registrar o surgimento de outra abordagem à mesma questão, cada vez mais atual pelas frequentes infrações dos direitos humanos na perspectiva global.

No livro Mengele's skull, do arquiteto israelita E. Weizman e do crítico literário norte-americano T. Keenan, os autores sugerem que o processo de identificação das ossadas de Josef Mengele, encontradas em 1985 na cidade de Embu das Artes, no Estado de São Paulo, provocou a emergência de uma mudança paradigmática no processamento de restos humanos e sua exposição como evidência nos fóruns legais.

A investigação em torno da fuga de Mengele para a América do Sul gerou a hipótese de que o criminoso teria vivido seus últimos anos em São Paulo, sob identidade falsa 
até morrer afogado em 1979. Quando, seis anos mais tarde, sua cova foi aberta, deu-se início a um processo investigativo inaugurando o que Keenan e Weizman (2012) chamam de um paradigma forense marcadamente diferente do paradigma documental que caracterizara os processos de Nuremberg, por um lado, e o paradigma testemunhal identificado com o processo de Eichmann em Jerusalém. No caso do suposto cadáver de Mengele, o desafio para a equipe de legistas era concluir, com uma certeza científica mais forte do que a probabilidade circunstancial, que a ossada encontrada era do esqueleto do médico nazista.

No âmbito da investigação forense, o objetivo normalmente é determinar o que exatamente ocorreu na cena do crime, mas, no caso da ossada de Mengele, a interrogação era outra. A pergunta aqui era: Quem é você? Tratava-se de identificar os restos do esqueleto a partir de uma perspectiva biográfica, procurando nos ossos sinais gravados de ocorrências vividas: acidentes, violências, doenças. Assim, as ossadas eram interpretadas como uma imagem da vida vivida, como se fosse uma superfície sensível maculada pela exposição à vida, assim como uma fotografia é resultado da exposição à luz rebatida sobre o objeto. O médico legista responsável, o norte-americano Clyde Snow, batizou esse trabalho de identificação dos restos humanos de biografia dos ossos: osteobiografia.

A analogia com o mundo das imagens não foi gratuita, nem a importância das imagens para conseguir evidenciar a identidade entre as ossadas e a pessoa em questão. Com o uso das novas tecnologias de vídeo e de exposição fotográfica, a equipe realizou a gravação de imagens da vida de Mengele sobrepostas à caveira encontrada, o que permitiu convencer os juízes da coincidência perfeita entre o objeto (a caveira) e a pessoa (o rosto de Mengele).

Foi uma conclusão científica importante, a inauguração de uma nova exposição tecnológica dos fatos. Entretanto, mais importante do que o avanço tecnológico foi, segundo 
Keenan e Weizman (2012), o reconhecimento do desafio retórico intrínseco do processo. Nesse sentido, fundiram-se, durante o processo, a dimensão da representação com a dimensão da exposição: por um lado, houve a representação dos ossos no fórum (forense possui a mesma raiz latina de fórum) da justiça; por outro lado, o dispositivo técnico desenvolvido permitira que os objetos "falassem por si mesmos", como uma espécie de "linguagem das coisas". Weizman e Keenan acentuam essa dimensão retórica do paradigma forense, o qual explicita o sentido de uma estética forense exatamente na criação de um novo regime de visibilidade que se impõe com certa força política no convencimento do público. Trata-se de um processo complexo por abranger aspectos tecnológicos na análise dos registos e também discursivos e retóricos. Os autores sugerem que envolve a figura retórica da prosopopeia, definida como a fala em que o orador oferece aos objetos inanimados uma voz própria (Weizman 50 e Keenan, 2012, p. 28). A historiadora de arte francesa Jean-Marie Mondzain (2009) amplia essa analogia ao discutir o duplo sentido do termo prosopopeia. Significa tanto dar rosto à pessoa como fazer falar o que não possui rosto ou voz. Esse entrelaçamento entre verbo e imagem, entre ouvir e ver, está no conceito de Quintiliano de evidentia in narratione, ou seja, tornar visível e evidente ao narrar. Uma verdade que se mostra enquanto falada e, ao mesmo tempo, se impõe e convence. É essa fala que habita o visível que desloca a ilusão de uma presença e converte o visível em endereçamento à escuta, em uma mensagem implícita do exposto compreensível para o interlocutor.

Voltando ao livro de Teixeira Coelho, podemos caracterizar alguns traços estruturais e enunciativos definidores de sua narrativa na perspectiva desse desafio retórico colocado pela estética forense. Lembremos a estrutura particular do romance formado por cinco "livros", dos quais já mencionamos quatro. $\mathrm{O}$ quinto tem o mesmo título do romance - 
História natural da ditadura -, o que convida o leitor à reflexão sobre seu significado particular. A leitura dessa parte rapidamente revela que é aqui que a estrutura se amarra na figura do quincunx, cinco partes em que quatro formam um quadrado centralizado pela quinta parte como nos cinco pontos de um dado. Essa figura é clássica e descreve tanto uma forma de plantação, uma técnica de jardinagem e irrigação, formações militares, estruturas moleculares, figurações astrológicas e místicas e formas retóricas. É também uma maneira simples de compor cinco partes, como acontece no livro, e em que o elemento central e final amarra as quatro. A inspiração para a apropriação do quincunx, Teixeira Coelho encontra no romance Os anéis de Saturno, em que o autor, o alemão Winfried Georg Sebald, adota a figura do escritor e personagem Thomas Brown, o qual, no livro Garden of Cyrus, de 1698, discute o princípio do quincunx. No clássico de Brown, a meditação sobre a universalidade desse princípio de composição procura mostrar a relação entre natureza e arte e a divina ordem geométrica e estética na realidade objetiva do mundo. Não é casual que Teixeira Coelho se aproprie exatamente desse elemento que indica, para Sebald, uma possível latência narrativa procurada por trás das vagâncias de seus personagens. A inspiração de Sebald está presente em muitos aspectos do romance de Teixeira Coelho, a começar pelo título - História natural da ditadura -, que remete ao livro de ensaios Luftkrieg und Literatur, intitulado na tradução portuguesa como História natural da destruição (Sebald, 2003 [1999]). Essa versão retoma claramente a ideia benjaminiana, amplamente presente em Sebald, de uma história natural como alternativa à história humana ou de uma naturalização da história humana. Assim, como em Benjamin e em Sebald, encontramos no estilo do ensaísmo ficcional um esforço de superar o depoimento subjetivo na análise e interpretação de constelações objetivas. Se os quatro pontos do quincunx representam as quatro perspectivas testemunhais cardinais, 
o quinto demarca uma estrutura objetiva, porém latente e não visível a olho nu, que permite relacionar as singularidades das vivências relatadas e a repetição de certas figurações aparentemente amarradas a determinações trágicas: o suicídio enigmático, a perda culpada do filho ou da filha e a tentação do poder entre outras. Assim, o jogo com o realismo neoplatônico e especulativo do quincunx, proveniente da ideia renascentista do mundo como um livro em que se pode enxergar a assinatura divina, desencadeia uma hermenêutica extrema, que permite identificar relações estruturais entre fenômenos naturais e artificiais, assim como entre eventos históricos e contingências biográficas, e sugere uma determinação imanente por trás do arbítrio subjetivo de uma história de vida conduzida pelo amor, pela arte e pelo idealismo devoto de uma causa maior.

O narrador de Teixeira Coelho não abre mão da sensibilidade subjetiva de observação e de memória, mas a escrita 52 é um exercício de interpretação objetivo, em que o discurso é chamado para o real através das fotos inseridas, dos fatos e nomes, índices dêiticos de um real os quais amarram a narrativa a determinado tempo e espaço. Não por acaso, um exemplo significativo é encontrado no artista argentino León Ferrari, amigo do autor que o presenteia com uma obra, na realidade um caderno com recortes recolhidos durante os anos mais duros da ditadura militar argentina. O caderno foi iniciado em 1976 e era um conjunto de notícias em que os assassinatos e desaparecimentos apareciam indicialmente sem endereçamento político de denúncia. Quando publicado no exílio em poucos exemplares, o título dado fora Nosotros no sabíamos e explicitava uma denúncia cujo conteúdo precipitava como em um processo químico que deixa um coágulo duro obstruindo a livre circulação das palavras e dos signos. São evidências cuja força não é revelar algo desconhecido, pois já sabemos do que fala, e, por isso, seu esforço de incluir a realidade na escrita não deve ser confundido com docu- 
mentarismo. Não se tratava de levar a realidade à literatura, senão intervir na vida tratada por via da literatura e segurar esses sinais comprometendo a escrita ao desafio do índice.

Assim como se mostrou uma tensão epistemológica na cultura contemporânea entre uma perspectiva testemunhal e uma perspectiva forense, entre a empatia subjetiva diante da valorização de certo objetivismo engajado, o argumento desse ensaio tornou possível entender parte da produção literária e artística em tensão análoga entre um extremo, que em uma voz subjetiva enfrenta aniquilação na aproximação à experiência traumática, e outro, em que os restos, os indícios e os objetos ganham voz e vida implacavelmente, na medida em que a escrita se conduz pelo esforço de seguir e interpretar suas complexas constelações. No exemplo do romance $K$. Relato de uma busca, de Bernardo Kucinski, o resultado estrutural desse limite subjetivo refletiu-se diretamente na composição de um romance complexo e fragmentado, sustentado pela elipse implícita. O romance de Teixeira Coelho, por sua vez, projetou-se num ensaio ficcional comprometido com a exploração melancólica de uma realidade objetiva e autoritária, por via da interrogação histórica das ditaduras do século XX, sem abrir mão da experiência autobiográfica.

\section{Karl Erik Schollhammer}

é professor e diretor do Departamento de Letras da Pontifícia Universidade Católica do Rio de Janeiro (PUC-Rio), pesquisador do CNPq e Cientista do Nosso Estado da Faperj.

\section{Bibliografia}

COELHO, T. 2006. História natural da ditadura. São Paulo: Iluminuras. FELMAN, S.; LAUB, D. 1991. Testimony: crises of witnessing in literature, psychoanalysis and history. London: Routledge 
KEENAN, T.; WEIZMAN, E. 2012. Mengele's skull-the advent of a forensic aesthetics. Berlin/Frankfurt a.M.: Sternberg Press/Portikus.

KUCINSKI, B. 2012. K. - Relato de uma busca. 2. ed. São Paulo: Expressão Popular. . 2014. K. - Relato de uma busca. São Paulo: Cosac Naify.

LONG, J. J. 2010. W. G. Sebald: image, archive, modernity. New York: Columbia University Press.

MONDZAIN, J.-M. 2009. A imagem pode matar? Lisboa: Passagens.

RANCIÈRE, J. 2014. Figures of history. London: Polity Press.

SEBALD, W. G. 1995. Die Ringe des Saturn. Eine englische Wallfahrt. Frankfurt a.M.: Eichborn. . 2003 [1999]. História natural da destruição. Lisboa: Teorema.

TEIXEIRA COELHO Netto, J. 2006. História natural da ditadura. São Paulo: Iluminuras.

WEIZMAN, E. 2012. Forensic architecture: notes from fields and forums.

Ostfilden: Hatje Cantz (100 notes, 100 thoughts, Documenta 13, v. 62). 


\section{A HISTÓRIA NATURAL DA DITADURA}

KARL ERIK SCHOLLHAMMER

Resumo: A partir da leitura de dois romances contemporâneos (K. - Relato de uma busca, de Bernardo Kucinski, e História natural da ditadura, de Teixeira Coelho), este ensaio analisa a relação da literatura brasileira recente comprometida com fatos históricos no contexto da ditadura militar. Irá arguir que tais romances refletem duas abordagens opostas ao desafio de dar conta de uma realidade de violência e repressão: uma adotando o prisma do testemunho subjetivo e outra se aprofundando no resgate dos elementos materiais de estruturas recursivas da história.

Palavras-chave: Romance Histórico; Ditadura Militar; Literatura Brasileira.

\section{THE NATURAL HISTORY OF DICTATORSHIP}

Abstract: From the reading of two contemporary novels (K. - Relato de uma busca, of Bernardo Kucinski, and História natural da ditadura, of Teixeira Coelho), this essay analyses the relation of recent Brazilian fiction to Historical facts in the context of Military Dictatorship. It will be argued that these two novels express two different approaches to the challenge of dealing with the reality of violence and repression: one adopting the lens of the subjective testimony and the other to the rescue of material elements of History's recursive structures.

Keywords: Historical Novel; Military Dictatorship; Brazilian Literature.

Recebido: 30/07/2015 Aprovado: 13/08/2015 